\title{
Evaluation of hydrodynamic effects on elevated cone-shaped water tanks
}

\author{
G. De Martino ${ }^{1}$, F. De Paola ${ }^{1}$, M. Giugni ${ }^{1} \&$ N. Fontana ${ }^{2}$ \\ ${ }^{1}$ University of Naples Federico II, Department of Hydraulic and \\ Environmental Engineering G. Ippolito, Italy \\ ${ }^{2}$ University of Sannio - Benevento (IT), Department of Engineering, Italy
}

\begin{abstract}
In this paper a model is discussed that allows a simple calculation of seismic effects on an elevated water cone-shaped tank. In particular, following on from the complete model of De Stefano and by means of the classic mechanical approach introduced from Housner, a definition of a circular tank in volumetric and seismic way equivalent to the cone-shaped one has been obtained, permitting the evaluation of the hydrodynamic effects by means of easy to use formulations. Keywords: seismic design, elevated cone-shaped water tanks, hydrodynamic effects.
\end{abstract}

\section{Introduction}

A suitable seismic response of hydraulic infrastructures (dams, tanks, distribution networks, water-drainage system etc.) allows for the development of an effective program of immediate aid to the hit areas and also the following measures aimed at the economic and social recovery, like events that took place recently in Italy have put into evidence. It is essential, therefore, that the seismic design of infrastructures could assure their reliability, by means of a suitable preliminary evaluation of the acting forces and a careful modelling of the right structural dynamic response, non neglecting, at the same time, the possibility to use devices for the mitigation of the seismic forces $[2,13]$.

In order to estimate the hydrodynamics actions induced on the hydraulic containers, to be added obviously to the hydrostatic push and the inertial actions connected to the structural masses in order to define the design input, there are many research works in progress at the Department of Hydraulic and 
Environmental Engineering "G. Ippolito" of the University of the Studies of Naples "Federico II", aimed, in first phase, to the dams [4, 6] and, subsequently, to the hydraulic containers, buried or half buried $[5-8,13]$ and elevated $[9,10]$ and to the water distribution networks [11].

In the present study, in particular, we analyze elevated cone-shaped water tanks. After a brief discussion on the previous studies on the dynamics answer of the elevated containers and on cone-shaped ones [9, 10, 12], we discuss a model that allows a simple and fast calculation of the impulsive forces induced on a cone-shaped water tank.

\section{Dynamics analysis of an elevated tank: literature review}

The dynamics analysis of an elevated tank can be run, generally, with reference to the following structural outlines:

- rigid scheme, considering not deformable column and tank, and assuming, therefore, a dynamic behaviour similar to the one of a block (reliable obviously only for "squat" structures);

- $\quad$ elastic scheme, considering the deformability of both the column and the container;

- mixed scheme, considering deformable the rigid column and the container.

The choice of the scheme, obviously, has to be carried out with reference to the real structural features of the column-tank system considered: material employed, shapes and sizes of the elements.

In the previous studies [9, 10], it was considered an elevated tank in reinforced concrete, with circular pond and a tapered connection to the column, such to assure a condition of mutual joint. It has been neglected the deformability of the pond, and was assumed, therefore, a mixed scheme about the features of the structural system.

Now we have to say that, while a container lying on the ground is directly affected by the seismic acceleration to its base, in an elevated tank all the masses absorb the dynamic energy transmitted by the foundation block through the elasticity of the column. The dynamic answer of the liquid, therefore, can be considered equivalent to the one of tank lying on ground, provided the acceleration of the ground must be replaced by the one of the pond-liquid system.

In order to analyze the dynamic answer of an elevated tank, previous studies $[9,10]$ made reference to the elastic console with distributed mass scheme with mass concentrated in head, considering the pond supported by a single vertical connection to the ground. Obviously the mass of the liquid has to be computed into the energetic budget of the structural system, assuming that it remains constant during the seismic event. It has been assumed, moreover, that the oscillations of the liquid in the container don't give place to meaningful modifications of the total answer of the system. 
It has been developed a dynamic module that analyses the dynamic response of the system, identifying the characteristic of the deformation in the fundamental vibration mode and the corresponding structural participation factor [9].

The results have been summarized in fig. 1, in which the value of the vibration period $T_{s}$ of the structural system has been reported in function of $m$ $\mathrm{H}_{\mathrm{T}} / \mathrm{M}$ ed $\alpha$, where:

- $\quad \mathrm{m}$ : distributed mass fort length unit of the column;

- $\mathrm{M}$ : concentrated mass of the tank and of the liquid;

- $H_{T} \cong H_{C}+H_{r}+0.5 \cdot H_{s}$;

- $\mathrm{H}_{\mathrm{c}}$ : column height;

- $\mathrm{H}_{\mathrm{r}}$ : joint element column-pond height;

- $\mathrm{H}_{\mathrm{s}}$ : water tank height;

- $\beta=H_{T} \cdot \sqrt[4]{\frac{m}{\mathrm{EI}}} ;$

- E: Young's modulus;

- I: moment of cross inertia of the column.

The results, summarized in fig. 1, show that:

- the period $\mathrm{T}_{\mathrm{s}}$ tends to increase when $\mathrm{M}$ increases, which means, in particular, when the volume of the liquid in pond increases;

- the $\mathrm{T}_{\mathrm{s}}$ period tends, also, to increase when $\mathrm{H}_{\mathrm{T}}$ grows and when $\mathrm{I}$ decreases (it increases as column thickness decreases) .

It has been also developed an hydraulic procedure (based on the Bratu model, suitably extended to circular section $[1,10])$, finalized to the calculation of the oscillation period of liquid in the container in the first mode of vibration, of the maximum elevation of the liquid during oscillation, of the pressures hydrodynamics distribution on the wall of the pond and the resulting force.

For the elevated cone-shaped tanks, it has been considered the structural scheme in fig. 2, made of reinforced concrete or, more frequently, in pre compressed reinforced concrete. According to the structural and elastic features of the previous column-pond system considered, the results achieved with the dynamic module, summarized in fig. 1, can be considered substantially still valid.

By that diagram it is possible to evaluate the vibration period of the structural system $\mathrm{T}_{\mathrm{s}}$, by which, given a design response spectrum, it is possible to determine the pseudo-acceleration $\mathrm{A}_{\mathrm{s}}$ to apply to the pond.

Below it is presented the hydraulic model developed for the cone-shaped container, for the calculation of the hydrodynamic forces.

Under seismic action, the liquid content in a tank performs the following dynamic actions:

- $\quad$ impulsive pressure, synchronized with soil acceleration;

- convective pressure (of "long period"), generated by the liquid oscillations (of $\mathrm{T}_{\mathrm{w}}$ period in the first mode); 
- impulsive pressure of "short period", generated by the container wall deformation and, so, by relative acceleration of the shell with respect to the soil.

In the hypothesis of a rigid container - in compliance with what said before - it is possible, obviously, to limit the analyses to the only impulsive and convective component, neglecting the "short period" ones.

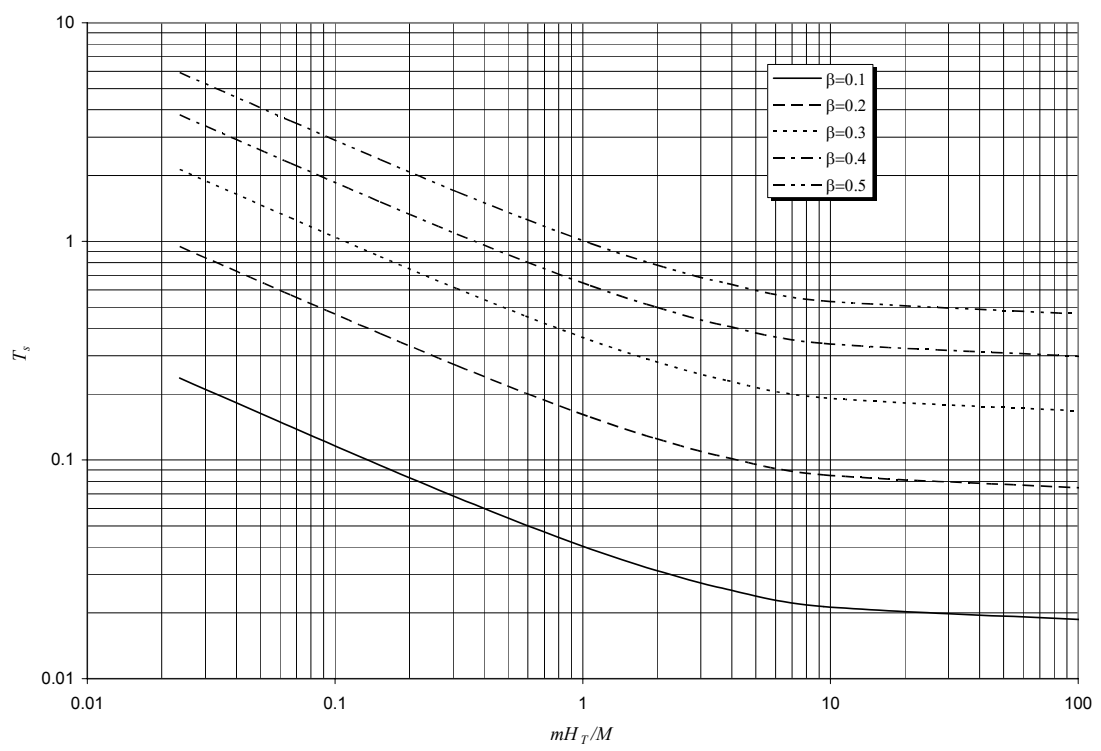

Figure 1: Vibration period of structural system function of $\mathrm{m} \mathrm{H}_{\mathrm{T}} / \mathrm{M}$ e $\alpha$ (De Martino et al. [10]).

On the basis of the same hypotheses adopted by Housner [14-16] and with reference to a tank with conical section (fig. 3) De Stefano [12] elaborates a model based on the subdivision of the fluid mass in sheets of infinitesimal thickness, delimited and separated one another by flat horizontal surfaces, in quiet state. During the motion such ideal surfaces oscillate, and incline of a corner $\theta$ depending on the $y$ height related to the top of the ideal cone and the $t$ time, like represented in the outline of tab. 4.

The hydrodynamic actions can be readily derived from the mechanical equivalent system in fig 2 . The convective push can be evaluated as an action of a concentred mass mc linked to the wall by means of spring of rigidity $\mathrm{k}_{\mathrm{c}} / 2$, while the impulsive action can be assimilated to a fixed mass $\mathrm{m} 0$ applied to a distance $\mathrm{h}_{\mathrm{m} 0}$ from the vertex of ideal cone (fig 2).

While delaying the complete explanation about the determination of the convective pressures, for the study of the impulsive effects, in particular, which 
are more complicate to determine, De Stefano [12] proceeds to the solution of Laplace equation with the following boundary conditions:

- $\quad$ flat free surface and absence of pressures on it;

- $\quad$ null vertical speed on the bottom of the tank;

- $\quad$ speed of the fluid square to the wall of the tank and equal to the corresponding speed of the wall.

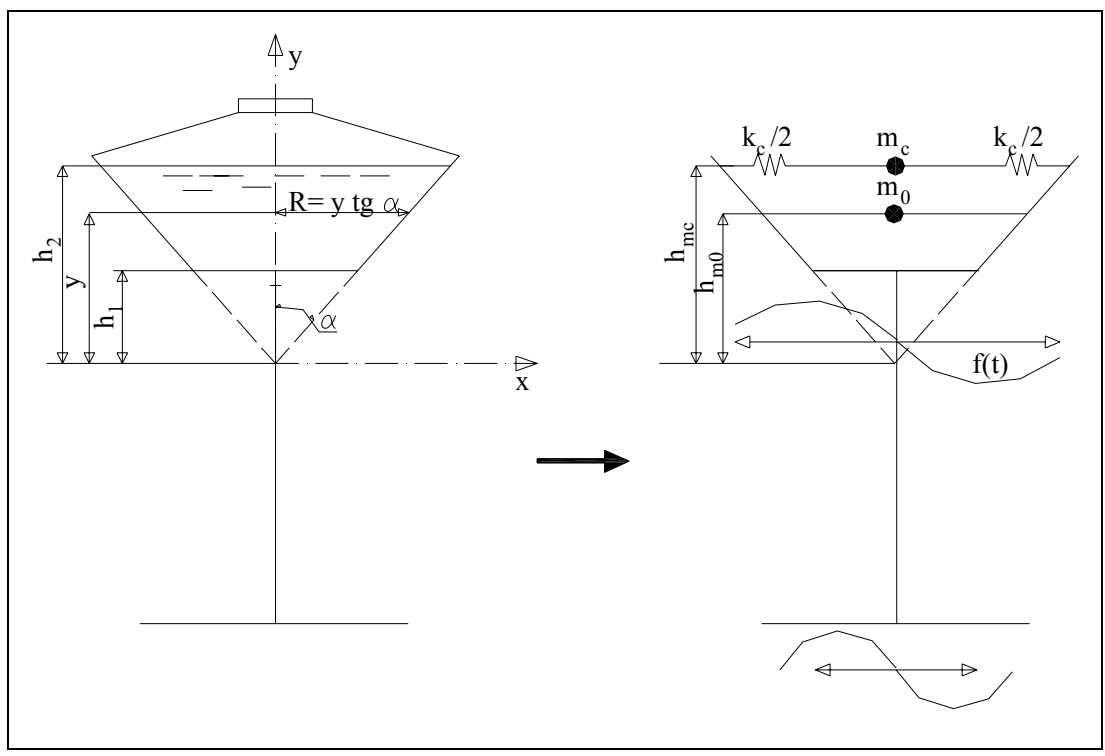

Figure 2: Cone-shaped water tank scheme and its mechanical model.

By the solution of the linear motion equation, the author reaches the following expression of the impulsive $p_{i}$ pressures distribution on the walls of the tank:

$$
p_{i}=\rho \ddot{u} \cos \gamma \sum_{m=1}^{\infty} A_{m} \cos \left[k_{m}\left(y-h_{1}\right)\right] I_{1}\left(k_{m} \cdot y \cdot \operatorname{tg} \alpha\right)
$$

where:

- $\quad \ddot{u}$ soil acceleration;

- $\mathrm{km}=(\pi / 2)\left[(2 \mathrm{~m}-1) /\left(\mathrm{h}_{2}-\mathrm{h}_{1}\right)\right]$;

- $\quad \mathrm{I} 1$ is the modified Bessel function first kind, order 1;

- Am are some coefficients, depending on $\mu=h_{1} / h_{2}$ and $\alpha$, established by expression of velocity potential, given the mentioned boundary conditions. 

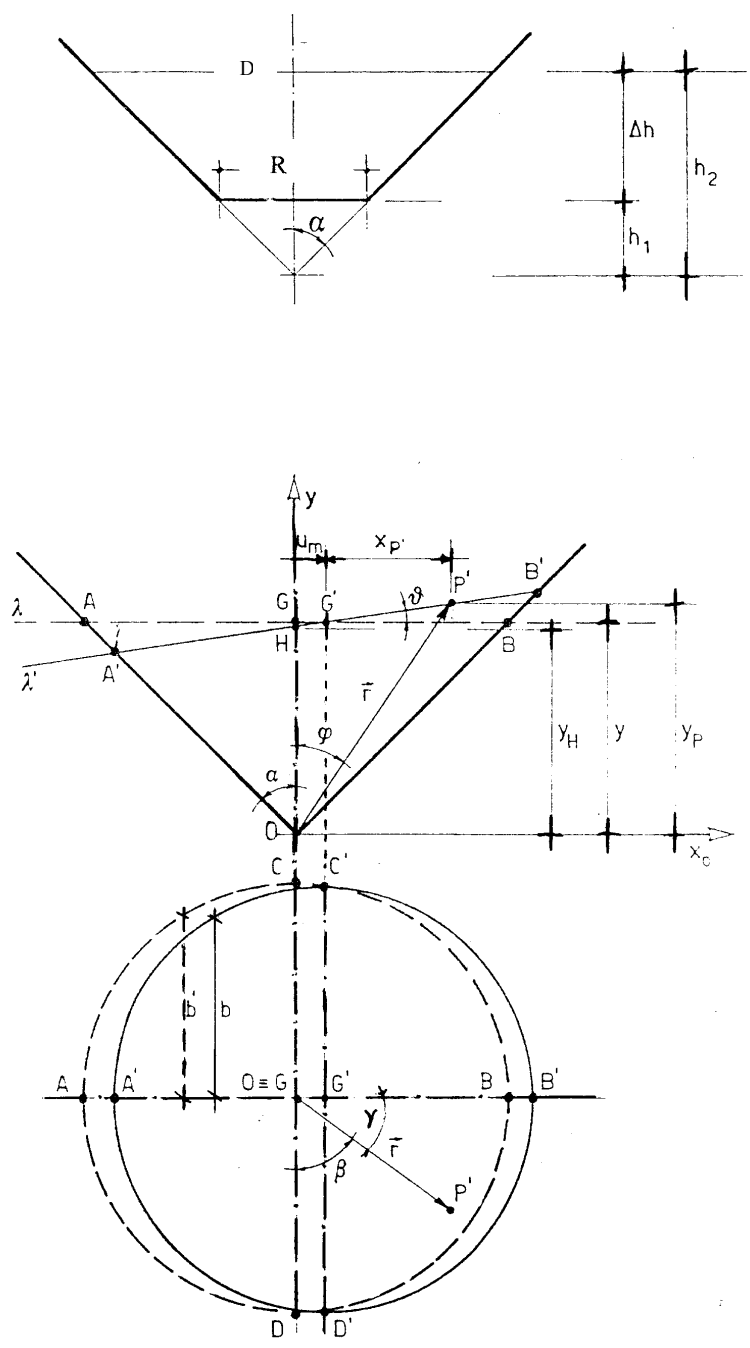

Figure 3: Geometric scheme of cone (De Stefano [12]).

For example it has been, also, represented in fig. 4 the course of the distribution of the impulsive hydrodynamics pressure, calculated making reference to a coefficient of seismic acceleration $\alpha^{\prime}=0.35$ on the wall of a conical tank having the geometric parameters: $h_{1} / h_{2}=0.20, \alpha=45^{\circ}$. As it can be seen on fig. 4 , the distribution of the impulsive pressures does not show the classic increasing course towards the bottom, typical of the circular and rectangular tanks, but it assumes a maximum in correspondence of depth approximately equal to $2 / 3$ of water depth. 


\section{Equivalent circular tank}

Given the application difficulties of the De Stefano [12] model, quite complex from the analytical point of view, some simplified ratios were gathered with reference to an ideal circular tank, equivalent to the conic one not only about the water volume but also in terms of hydrodynamic actions, in order to allow a rapid calculation of the hydrodynamic impulsive pressures. Since the horizontal component of the impulsive hydrodynamic push $\mathrm{S}$ is calculated, as already specified, by the product $m_{0} \cdot \ddot{u}_{0}$ (in which $\ddot{u}_{0}$ is unvarying), it has been imposed that the impulsive equivalent mass of the ideal circular tank and the corresponding of the conic one are coincident.

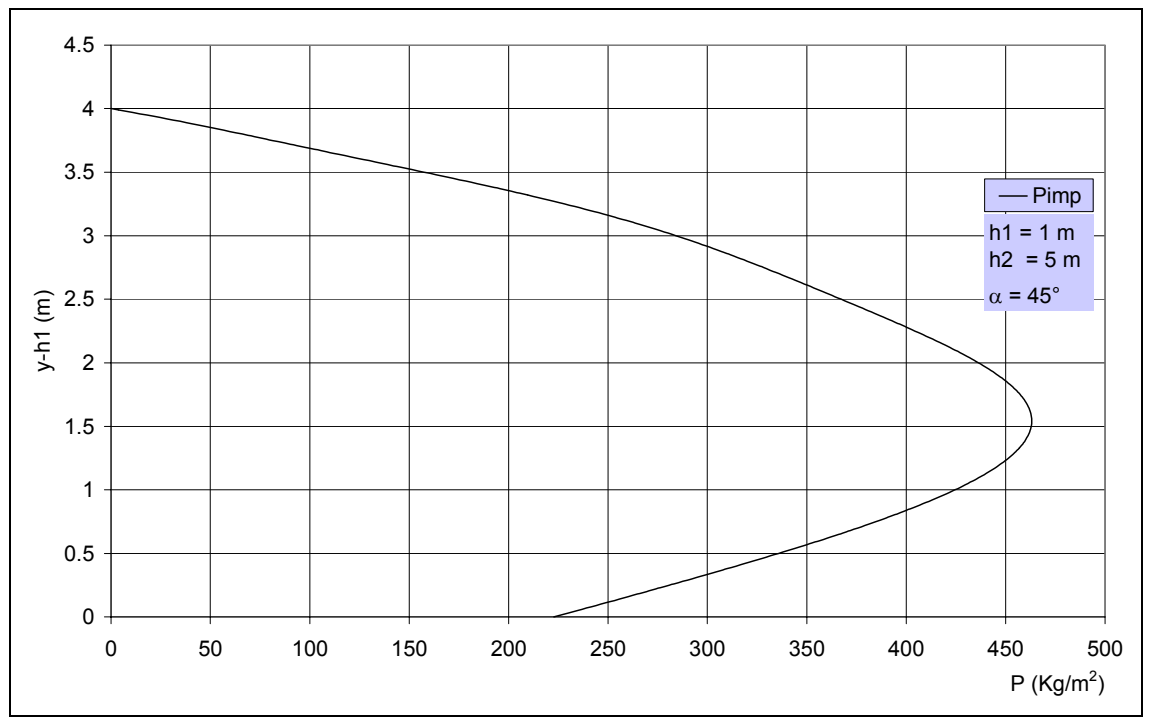

Figure 4: Pressure impulsive distribution for a cone-shaped water tank with $\mu=0.20$ e $\alpha=45^{\circ}$.

Using the Housner formula $[15,16]$ for the evaluation of the impulsive equivalent mass of a circular tank, we get to the following equation :

$$
\left(\mu_{0}\right)_{c i l}=\frac{\tanh (\sqrt{3} R / h)}{\sqrt{3} R / h}=\left(\mu_{0}\right)_{t c}
$$

where $(\mu \mathrm{o})_{\mathrm{cil}}$ is the impulsive equivalent mass of the cylindrical tank (with no dimensions in comparison to the real liquid mass), $\left(\mu_{0}\right)_{\mathrm{tc}}$ the one of the conic tank, that can be deduced by the expression $\left(\mu_{0}\right)_{t c}=1-\frac{m_{c}}{m}$ [12], $\mathrm{R}$ and $\mathrm{h}$ are respectively the radius and the water level of the ideal tank. 
Resolving numerically the equation (2), we get to the abacus of fig. 5, where it is shown the course of the ratio $\mathrm{R} / \mathrm{h}$ (as the angle $\alpha$ vary from $30^{\circ}$ to $60^{\circ}$ ) with $\mu=0,0.2,0.4$.

In fig 5 it is evident that the differences among the curves are minor, enlightening a scarce dependence of $\mathrm{R} / \mathrm{h}$ on this parameter, particularly for values which are technically more frequent of the ratio $\mu$ (from 0 to 0.20 ).

The following analytical expression of $\mathrm{R} / \mathrm{h}$ in function of $\mu$ and $\alpha$ has been drawn through a numerical regression:

$$
\frac{R}{h}=\frac{1}{\left(-5.68 \cdot \mu^{2}+1.94 \cdot \mu+3.48\right)+\left(1.30 \cdot \mu^{2}-0.48 \cdot \mu-0.80\right) \cdot \ln (\alpha)}
$$

Giving values of $\mu$ from 0 to 0.20 , as already observed, the ratio $\mathrm{R} / \mathrm{h}$ can be considered, in practice, independent from $\mu$ and function only of $\alpha$, according to the simplified expression:

$$
\frac{R}{h}=0.004 \cdot \alpha^{2}-0.24 \cdot \alpha+5.11
$$

that introduces very little offsets (around 7\%) in comparison to the (3).

By the geometry of the conic tank and through the (3) or the $\left(3^{\prime}\right)$, it is possible to reach easily to the value of the ratio $\mathrm{R} / \mathrm{h}$ of the equivalent cylindrical tank in terms of impulsive actions.

The condition of the equivalence of containers volumes has to be used, with the purpose to define the geometric characteristics of the ideal cylindrical tank:

$$
\pi R^{2} h=\frac{1}{3} \pi \tan ^{2} \alpha h_{2}^{3}\left(1-\mu^{3}\right)
$$

getting the height $\mathrm{h}$ of the equivalent cylindrical reservoir in function of the geometric characteristics of the conic tank:

$$
h=\left[\frac{\tan ^{2} \alpha\left(1-\mu^{3}\right)}{3(R / h)^{2}}\right]^{1 / 3} h_{2}
$$

For example, given a conic tank with the following dimensions, $h 1=1 \mathrm{~m}$, $\mathrm{h}^{2}=5 \mathrm{~m}, \alpha=45^{\circ}, \mu=0.20$, volume of $130 \mathrm{~m}^{3}$, on tab 6 or the (3) is shown that $\mathrm{R} / \mathrm{h}=$ 2.34 (from the $\left(3^{\prime}\right)$ is taken $\mathrm{R} / \mathrm{H}=2.41$, with a $3 \%$ offset) and, subsequently, on the $(5) \mathrm{h}=1.95 \mathrm{~m}$ (and therefore $\mathrm{R}=4.60 \mathrm{~m}$ ). Once $\mathrm{R}$ and $\mathrm{h}$ are known, it is possible, therefore, to appraise quickly the impulsive hydrodynamic mass agent on the equivalent cylindrical tank. With reference to the response spectrum of the European legislation EC8 (B) and to a seismic coefficient equal to 0.35, the ratio $\mathrm{S}_{\mathrm{i}} / \mathrm{S}_{\mathrm{w}}$ between the impulsive hydrodynamic push and the hydrostatics one for the cylindrical tank $(\mathrm{H} / \mathrm{R}=0.424)$ is around 0.53 [3]. The equivalent mass for the conic tank is equal to $\left(\mu_{\mathrm{o}}\right)_{\mathrm{tc}}=0.2435$ while for the equivalent cylindrical tank it is $\left(\mu_{\mathrm{o}}\right)_{\mathrm{cil}}=0.2466$ with $2 \%$ offset. Calculation made, has shown that the offsets between the horizontal component of the impulsive hydrodynamic push calculated with the De Stefano [12] complete model and the equivalent cylinder one is less than $3 \%$, varying $\mu$ e $\alpha$. Similar evaluations run by the application of (3') for conic tank characterized by values of $\mu$ between 0 and 0.20 , have led to maximum offsets never above $10 \%$. 


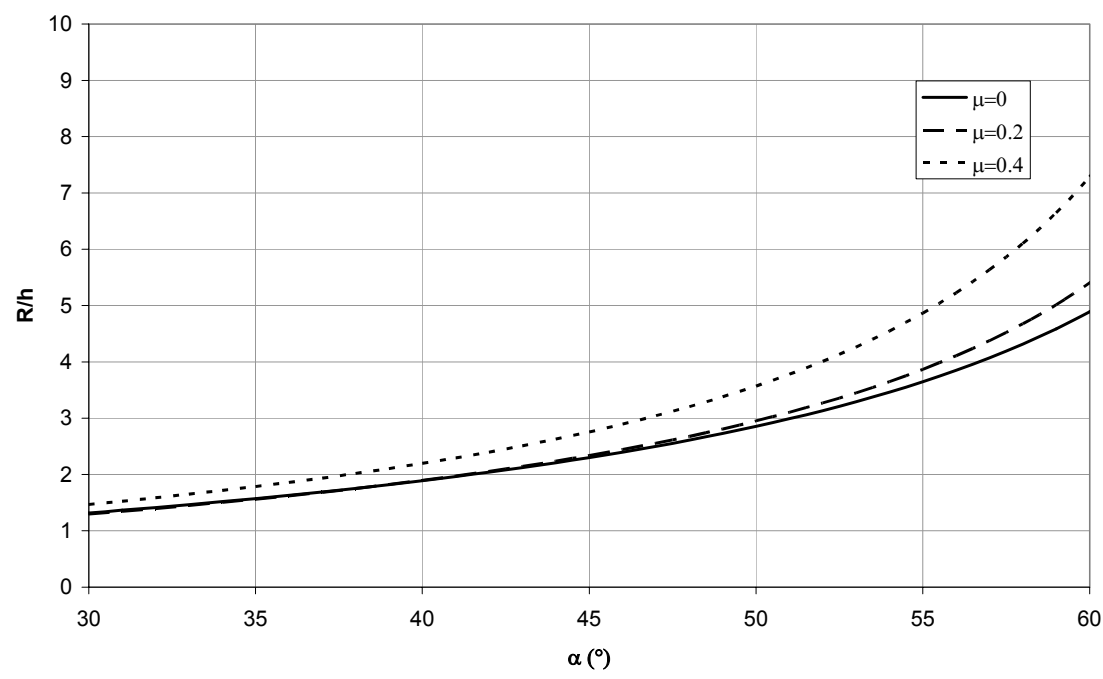

Figure 5: Value of $\mathrm{R} / \mathrm{h}$ of "ideal" tank varying $\alpha$ and $\mu=\mathrm{h}_{1} / \mathrm{h}_{2}$.

\section{Conclusive remarks}

In the present study a simplified methodology for the rapid evaluation of hydrodynamics impulsive forces on cone-shaped water tanks has been presented. From the theory of De Stefano the Authors have obtained, by means of Housner mechanical model, simplified analytical expressions for calculation of cylindrical water tank size to be equivalent to cone-shaped one from the seismic and volume perspective. Given the "ideal" tank geometry (radius and beam) it is possible, then, to define quickly the hydrodynamic impulsive push to be coupled to the convective one, which easier to calculate.

\section{References}

[1] Bratu, C. Sul comportamento in regime sismico dei liquidi contenuti in serbatoi rettangolari, Atti IX Convegno di Idraulica e Costruzioni Idrauliche, Trieste, 29 -31 Maggio 1965.

[2] Chalhoub, M.S., Kelly, J.M.. Shake table test of cylindrical water tanks in base-isolated structures, J. Engrg. Mech., ASCE, 116(7), 1421 - 1472, 1990.

[3] De Martino, F., De Paola, F., Giugni, M., Sulla valutazione delle azioni idrodinamiche sui serbatoi idraulici "rigidi", L'Acqua, n.6, 2005.

[4] De Martino, G., Giugni, M., Effetti idrodinamici sulle dighe di sbarramento durante i terremoti. Il Giornale del Genio Civile, Fasc. $4^{\circ}-5^{\circ}-$ $6^{\circ}, 1983$. 
[5] De Martino, G., Giugni, M., Azioni delle onde sismiche sui contenitori idraulici interrati, Il Giornale del Genio Civile, Fasc. 10-11 ${ }^{\circ}-12^{\circ}, 1989$.

[6] De Martino, G., Giugni, M., de Marinis, G., Hydrodynamic Pressures on Dams during Earthquakes - Approximate Formulation. Earthquake Resistance Engineering Structures, Thessaloniki, Greece 1996.

[7] De Martino, G., Giugni, M.. Seismic effects on waterworks, Excerpta, 1997.

[8] De Martino, G., Giugni, M., Perillo, G.. Serbatoi circolari in zona sismica - Valutazione delle spinte idrodinamiche, Atti delle Giornate di studio in onore del Prof. E. Orabona, 1997.

[9] De Martino, G., Giugni, M., Santorelli, S., Azioni idrodinamiche indotte da moti sismici su serbatoi pensili, Atti $8^{\circ}$ Convegno Nazionale ANIDIS L'Ingegneria Sismica in Italia, Taormina, 21-24 Settembre 1997.

[10] De Martino, G., Fontana, N., Giugni, M., Gravino, C., Serbatoi pensili in zona sismica. Azioni idrodinamiche, Atti $9^{\circ}$ Convegno Nazionale ANIDIS L'Ingegneria Sismica in Italia, Torino, 20-23 Settembre 1999.

[11] De Martino, G., Giugni, M., de Marinis, G.. Risposta dinamica di tubazioni di drenaggio in zona sismica, Idrotecnica, n.1, 1994.

[12] De Stefano, A., Sulla verifica antisismica approssimata dei serbatoi d'acqua tronco-conici in c.a., Atti dell'Istituto di Scienza delle Costruzioni, Politecnico di Torino, n623, 1983.

[13] Giugni, M., de Marinis, G., Perillo, G., Sovrappressioni idrodinamiche su contenitori deformabili in zona sismica. Atti $7^{\circ}$ Convegno nazionale ANIDIS “L'ingegneria sismica in Italia”, Siena, Vol. II, 1995.

[14] Haroun, M. A., and Housner, G. W., Seismic design of liquid storage tanks, J. Tech. Councils, ASCE, 107(1), 191 - 207, 1981.

[15] Housner, G. W., Dynamic pressures on accelerated fluid containers, Bull. Seismological Soc. of Am., 47(1), 15 - 37, 1957.

[16] Housner, G. W., The Dynamic Behaviour of Water Tanks, Bull. Seismological Soc. of Am., 53(2), 381 - 387, 1963. 